\title{
The Design and Analysis of Micro Learning System Based on WeChat Public Platform
}

\author{
Jiemei GAO, Jun HAN *, Jing LIU, Shuwei DONG, Nannan WANG \\ Capital Normal University Department of Educational Technology, Beijing, China.100048
}

\begin{abstract}
There, presently, are few micro learning resources based on WeChat public platform. The purpose of this paper is to create a micro learning system based on WeChat public platform which includes advantages of the combination of WeChat public platform and micro learning. Its aim is to provide a diversified, unique, contextual, intelligent, interactive, communicative platform for learners.

KEYWORD: WeChat public platform; Micro learning system; Micro notice; Micro resources; Micro forum
\end{abstract}

\section{OVERVIEW}

\subsection{The overview of micro learning}

There has no unified definition of Micro learning yet. Martin lindener, who is an Austrian study expert and the first to put forward micro learning, thought "micro study existing in the new media ecological system is a kind of learning model based on micro content and micro media". Domestic Xu Fuyin made a similar point of view "micro study is using a micro media bearing micro learning content". Thus, the two stressed two important factors of Micro learning: micro content and micro media. [1]

Micro content mainly includes: micro notice, micro outline, micro target, micro video, micro PPT, micro homework etc... Micro media currently popular mainly includes: QQ, MSN, Renren, blog, micro-blog, WeChat, WeChat public platform etc...

\subsection{The overview of WeChat public platform}

WeChat public platform which was officially launched in 2012-08-23, in addition to having some identical functions of the general social network such as instant and fission communication, has some unique features. After several versions of the update later, WeChat public platform mainly has the follow functions. (1)the mass function; (2)the function of the automatic reply; (3)management of the message, the user, material; (4)statistical analysis of the user, graphics, news, interface; (5)the custom menu; (6) providing programming interfaces for a certain third party. [2] Not only can these functions conveniently provide micro learning materials for learners in accordance with their needs and analyze some data based on behaviors of learners, but also makes the system more interactive through the self-defined custom and the secondary development.

\subsection{The current situation of the micro learning system based on WeChat public platform}

At present, there are few micro learning resources based on the WeChat public platform. Most WeChat public account about education mainly includes some distance education, vocational training and foreign language learning company. These companies generally take the WeChat public platform as enrolment propaganda tool to push a lot of advertising to the user, instead of making it provide the user with micro learning platform for learning resources. ${ }^{[3]}$ The purpose of this paper is to create a micro learning system based on WeChat public platform, providing diversification of learning resources for learners, to adapt to the different learners' learning styles and make the study more scenarios, intelligent and flexible. [4]

\section{THE FUNCTIONAL ARCHITECTURE OF MICRO LEARNING SYSTEM ON WECHAT PUBLIC PLATFORM}

\subsection{Micro learning system function structure diagram}

At present, custom menu of WeChat public platform include at most three one level menu and each one level menu contains at most five secondary level menu. A menu up to four Chinese characters, two menu up to seven Chinese characters, the extra part will be "..." instead. (This article is just designing a micro learning system, so the number of Chinese 
characters of the menu does not have limited.) It can be designed the functional frames based on the micro learning systems of WeChat public platform, according to the main content of micro learning. As is shown in Fig 1.

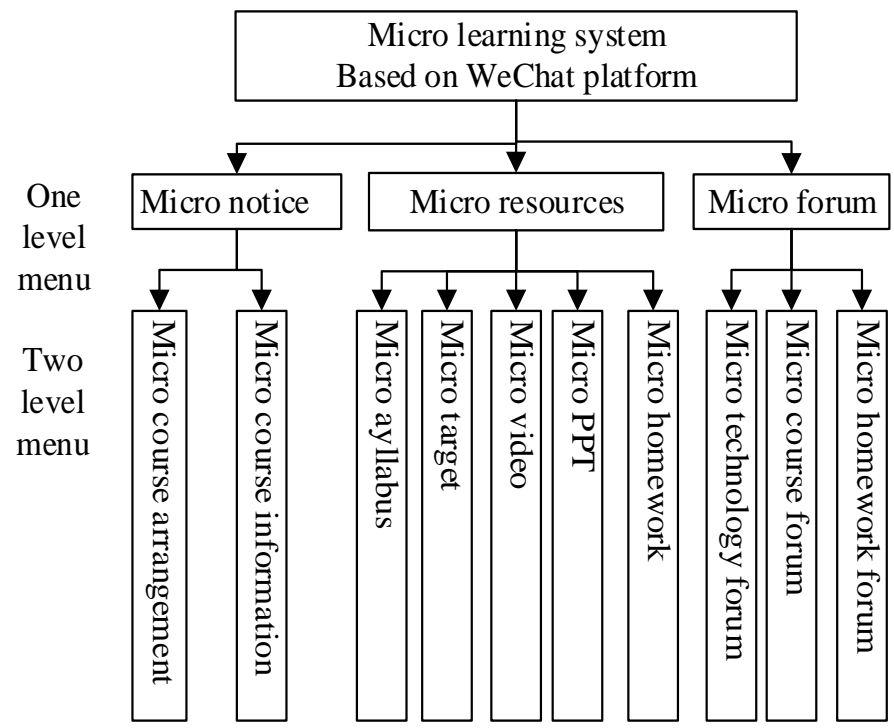

Fig. 1 Micro learning system function structure figure

The Fig 1 shows that micro learning system based on WeChat public platform mainly consists of three modules: micro notice, micro resources and micro forum. The micro notice mainly contains a number of basic course information. The micro resource is the key module of the system, which covers about various types of micro content, providing a rich resource for learners. The most special of micro forum is discussing respectively to create all types of content, so convenient for learners to access to relevant posts or meet the demand of learns' needs[5].

(1) Micro course arrangements: Micro course arrangements briefly introduce the course content every week to open, and the general commencement time.

(2) Micro course information: Micro course information mainly includes prerequisites and materials. Prerequisites are the description of existing knowledge that micro learners should possess. Materials are the description of the micro content, micro video, micro exercises.

(3) Micro outline: This is the description of micro course tentative outline.

(4) Micro target: Micro target can make learners quickly achieve in a short period of time, improve the learners' self-efficacy, and promote learning. ${ }^{[6]}$

(5) Micro video: MOOCs and Khan Academy video production experience is segmenting the traditional 45 minute class into 3-5 10 minutes of micro video. Because the micro learning system based on WeChat public platform is based on mobile terminal. In the absence of WIFI, browsing the video mainly rely on the $3 \mathrm{G} / 4 \mathrm{G}$ network, but $3 \mathrm{G} / 4 \mathrm{G}$ network currently in the browse the video stability is not very good and the video cost flow greatly. so the micro learning system requires segmenting a micro video within 5 minutes or the smaller, so that the users is convenient to learn in their own time slot. ${ }^{[7]}$

(6) Micro PPT: The PPT used through the micro learning should upload to the system, to facilitate the learners to download.

(7) Micro homework: learners can test their own learning content through micro homework to check whether they have achieved the micro learning objectives.

(8)Micro technical forum: micro technical discussion is mainly to discuss the technical problems encountered when using the micro learning system.

(9)Micro course forum: it is mainly to discuss the micro curriculum content issues.

(10)Micro operation forum: it is mainly to discuss the micro homework problems, but in the forum does not allow learners to discuss homework answer directly.

\subsection{The design of micro learning system cases}

This paper design micro learning system based on WeChat public platform taking Research Method of Educational Technology as an example. The Fig 2a is pushing basic information to the learners through WeChat public platform about Research Method of Educational Technology course. Fig 2b, Fig 2c and Fig $2 \mathrm{~d}$ show respectively the micro learning system one level menu and secondary level menu. Through every secondary level menu link, we can begin to study Research Method of Educational Technology course.

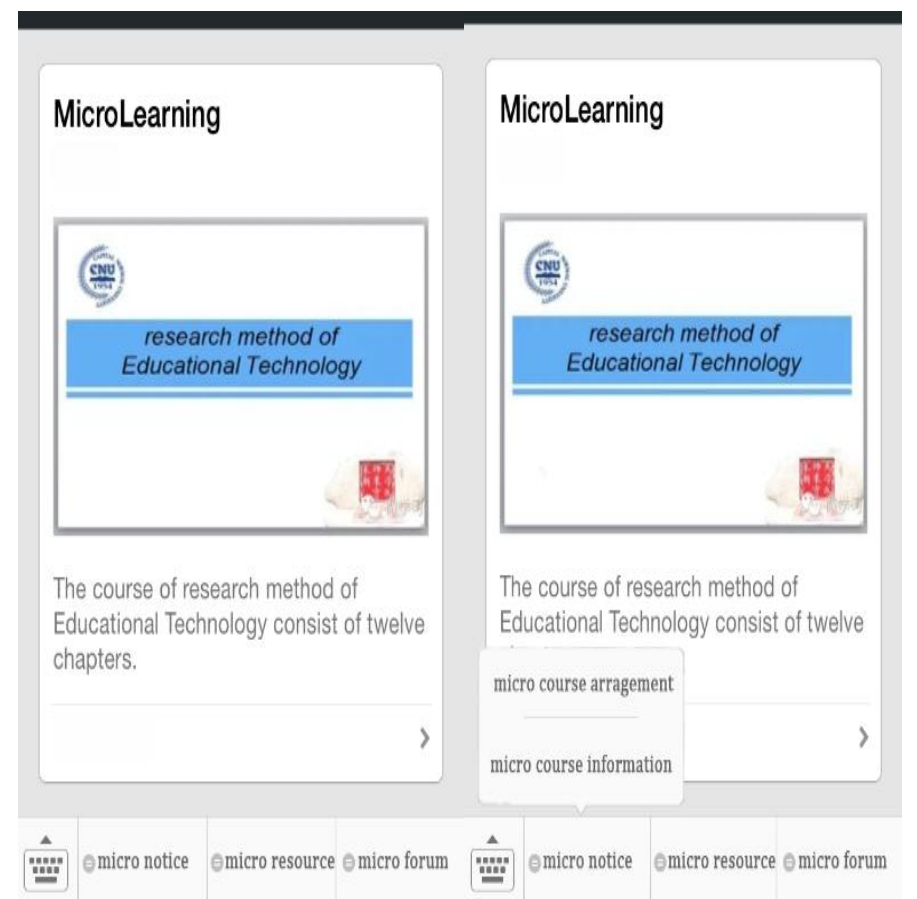

(a)

(b) 


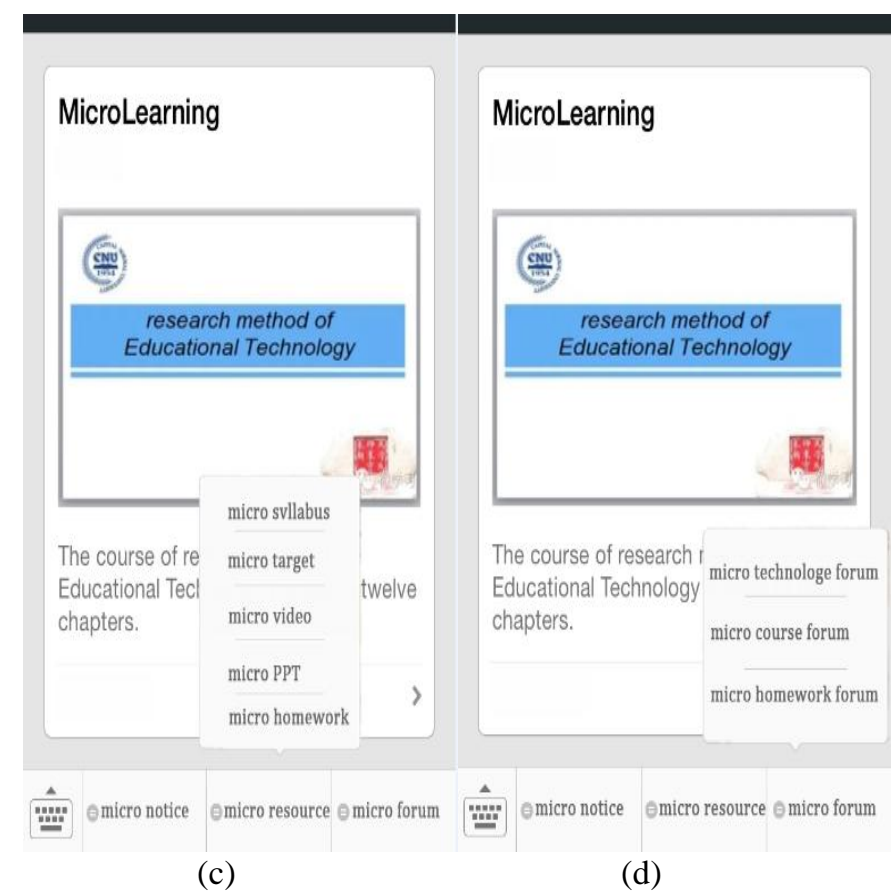

Fig. 2 The design of micro learning

The course of Research Method of Educational Technology consisting of twelve chapters, respectively is the introduction, the design of research plan, the method of literature research, content analysis, questionnaire survey, education statistics, interview method, observation method, experimental method, action research method, classroom teaching model and interactive quality research method, based on the network teaching interactive information research method. In the twelve chapters, in addition to the introduction and the design of research plan, the remaining ten chapters are some kind of specific research methods. Take the chapter of the action research method as an example to design the micro learning system.

(1) Micro course arrangements of action research method: This week will open the course of action research method. Action Research is researched and practiced by all person who are related to issues, can intervene the whole problem and find the relevant theoretical and research methods to solve practical problems in this activity. [8]

(2) Micro course information of action research method: Before learning action research must study the chapter of the design of research plan.

(3) Micro outline of action research method: The outline of the action research method will be described, as shown in Fig 3.

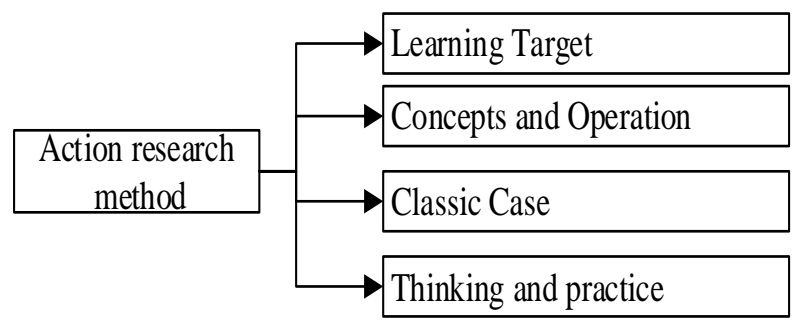

Fig. 3 Micro outline of action research method
(4) Micro target of action research method: Grasp the concept of action research; understand the characteristics of action research; learn the mode of action research; master the procedure of action research; eventually use an action research model to design and implement research plan. [9]

(5) Micro video of action research method: the main content of the action research method include: 1. the concept and characteristics. 2. Operation procedures. 3. Classic cases. According to the requirements of the micro learning system, micro video need to be divided into 5 minutes or the smaller. So the main contents of action research should be divided more subtle:

1.1 explain the basic concepts of action research.

1.2 explains the characteristics of action research.

2.1 explain the five kinds of patterns of action research.

2.2 explain basic aspects of action research.

2.3 explain the research procedures of action research.

3 explain classic case of action Research.

(6) Micro PPT of action research method: According to each section of the micro video of action research method, uploaded corresponding PPT to micro learning system to facilitate learner download.

(7) Micro homework of action research method: Micro homework either can be designed according each content of micro video or can be based on the final action research method to design a big homework. For example: according to Elliott action research program mode, design the action research plan following the pattern. Learners can upload homework and the teacher can judge it at same time.

(8) Micro technical forum of action research method: learners can discuss operational issues about micro learning systems encountered in the study, such as the video's playing form, buttons setting and so on. These can facilitate further improvements of the system.

(9) Micro course forum of action research method: Learners can discuss micro content about action research method, such as concept and characteristics and so on. Teachers can initiate topic posts.

(10) Micro operation forum of action research method: Learners can discuss homework of the action research method with each other, but not allow to directly telling the answer. So that learners can form a learning community which will help to learn.

\section{CONCLUSIONS}

The micro learning system based on WeChat public platform setting micro learning and WeChat public platform advantages in one, can provide flexible, 
diversified micro learning materials for learners, can brings a new experience, and can provide a rich interactive functions. At the same time, micro learning content can spread the fission type through WeChat public the platform, so that the micro learning content has been fully shared, broaden the learns' social relation network.

\section{ACKNOWLEDGEMENTS}

The research work is supported by the research project of university network learning support service system (KM201310028017).

\section{REFERENCES}

[1] Zhang Zhenhong, Yang Qingying, Han Zhi. Micro learning Research: current status and future. Chinese telephone education, 2013 (11): 12-20.

[2] WeChat public platform. https://mp.weixin.qq.com, 201501-09.
[3] Liu Yuting. The application and research of WeChat public platform in mobile learning. software guide, 2013 (10): 9192.

[4] Zuo Hongzhen, Han Jiawei, Jia Yanyang. Micro learning design in English teaching application based on portable terminals. China educational technology equipment, 2013 (12): 17-18.

[5] Gao Jiemei, Han Jun, Liu Jing, Wang Nannan, Dong Shuwei. The comparison and analysis of MOOCs Platform ---Take edX, Coursera, Udacity platform as an example. software guide, 2014 (12): 178-180.

[6] Yang Ziyan, Luo Qingqian, He Side. The study of personal learning environment model Construction based on micro information environment. China educational technology equipment, 2013 (12): 54-36.

[7] Zheng Xudong, Chen Lin, Chen Yaohua, Li Zhenchao.The implications of MOOCs to excellent resources sharing class construction. Chinese telephone education, 2014 (01): 76-80.

[8] Li Kedong. Research method of educational technology. Beijing: Beijing Normal University press, 2001.

[9] Zhang Yi, Zhou Ping Hong. Research method of educational technology. Beijing: Peking University Press, 2013. 